\title{
Compact Size UWB Monopole Antenna with Triple Band-Notches
}

\author{
Wael ALI ${ }^{1}$, Ahmed A. IBRAHIM ${ }^{2}$, Jan MACHAC ${ }^{3}$ \\ ${ }^{1}$ Dept. of Electronics \& Comm. Engineering, College of Engineering, Arab Academy for Science, Technology and \\ Maritime Transport (AASTMT), Alexandria, Egypt \\ ${ }^{2}$ Dept. of Electrical Engineering, Faculty of Engineering, Minia University, Minia, Egypt \\ ${ }^{3}$ Dept. of Electromagnetic Field, Faculty of Electrical Engineering, Czech Technical University in Prague, Czech Republic
}

wael_abd_ellatif@yahoo.com, ahmedabdel_monem@mu.edu.eg,machac@fel.cvut.cz

Submitted August 31, 2016 / Accepted January 13, 2017

\begin{abstract}
This paper presents triple band notched ultra wide band (UWB) monopole antenna with overall size of $36 \times 32 \mathrm{~mm}^{2}$ fed by microstrip transmission line. In order to achieve a good impedance matching from $2.7 \mathrm{GHz}$ to 13.4 GHz, a tapered transition between the rectangular patch and the feeding line is utilized. The three notched frequency bands are accomplished by a defected microstrip structure (DMS) which is inserted in the microstrip feeding line and by an open loop slot etched in the radiating patch. The three band notches are 3.15-4 GHz, 5.7-6.3 GHz and 7.9-8.6 GHz. They prevent the receiving of the signals of IEEE 802.16 WiMAX band, WLAN band, and ITU applications respectively. The UWB antenna was designed and simulated, then fabricated and tested in order to investigate its impedance and radiation characteristics. Good agreement between the simulated and measured data is achieved. The obtained results show that the proposed antenna is convenient for UWB applications.
\end{abstract}

\section{Keywords}

UWB monopole antenna, open loop resonant slot, defected microstrip structure, notched characteristic

\section{Introduction}

Recently, the rapid growth in the field of wireless communications and electronics has been extended. Ultra wide band (UWB) antennas play critical role in the UWB communication systems. The UWB antennas are designed to cover range $3.1-10.6 \mathrm{GHz}$ assigned by FCC (Federal Communication Commission) [1]. The UWB technology has several advantages such as high data rate, low power consumption, simple hardware configuration in practical applications and good resistance for multipath [2], [3]. The UWB antenna is considered as one of the important components to realize the UWB communication systems. Therefore, UWB antenna has to achieve several requirements such as high and stable gain, omnidirectional radiation pattern, wide impedance matching through all frequency bands, low cost and compact size [4], [5].

Presently, printed UWB monopole antennas are used due to their merits such as small size, easy of fabrication, low cost and their compatibility with RF components [6-10]. However, there are many narrowband communication systems that interfere with the UWB systems such as WiMAX (3.3-3.7 GHz), IEEE $802.11 / \mathrm{b} / \mathrm{g} \quad(5.15 \mathrm{GHz}$ to $5.825 \mathrm{GHz}$ ) WLAN band and X-band operating at $7.725 \mathrm{GHz}$ to $8.275 \mathrm{GHz}$ for ITU applications. In order to reduce the potential interferences from these undesired narrowband signals, UWB antennas with filtering behavior (notched characteristics) are designed. There is a number of antennas of this type presented in literature working with different elements assuring the notched characteristic - stop-bands. Some of them are: Paper [11] presents the antenna using the stepped impedance resonator and forkshaped stubs. The antenna presented in [12] applies an annular strip etched above the radiating element and two slots, one C-shaped and one arc-shaped embedded in the radiating patch. Rather complex resonator enlarging the area taken by the antenna is used in [13]. Microstrip twoport filtering structure composed of a couple of modified capacitance loaded loop resonators is used in [14]. Each antenna designed in [15] comprises a half-circle shaped patch with an open rectangular slot and a half-circle shaped ground plane.

In this paper, a compact microstrip fed monopole UWB antenna with three stop bands and overall size of $36 \times 32 \mathrm{~mm}^{2}$ is presented. The notched frequency bands are achieved by employing open loop resonator etched in the patch and defected microstrip structure (DMS) stopband filter inserted in the feeding line. First of all, a reference antenna is designed, which exhibits radiating characteristics in the frequency band 2.7-13.4 GHz. The first and the third notches are achieved by using DMS at frequency bands $(3.15-4 \mathrm{GHz}$ and 7.9-8.6 GHz). The second notch is achieved by using open loop slot at frequency band (5.7-6.3 GHz). The proposed antenna has been designed, simulated, fabricated and measured. The designed antenna 
performance has been validated using the electromagnetic full wave simulations. The commercial software HFSS was employed in the full wave simulations.

\section{Design Procedures}

\subsection{UWB Antenna Configuration}

The UWB antenna design is comprised of the steps: First of all, conventional patch antenna with partial ground plane is designed (case I) to achieve UWB behavior from $3.1 \mathrm{GHz}$ to $10.6 \mathrm{GHz}$ as shown in Fig. 1(a). The VSWR of this antenna plotted in Fig. 2 shows that the antenna operates from $3.5 \mathrm{GHz}$ to $6.5 \mathrm{GHz}$ with VSWR lower than 2 . Matching of the UWB antenna can be improved by using a tapered transition in the radiator (case II) as illustrated in Fig. 1(b). The VSWR of the designed antenna illustrates that the antenna works from $3.1 \mathrm{GHz}$ to $12 \mathrm{GHz}$ (UWB applications). Finally to achieve good matching properties, simple rectangular slot is added in the ground plane (case III) as shown in Fig. 1(c). The case III is therefore used as our reference UWB antenna. The wide band operation of the UWB antenna has been achieved by optimizing the dimensions of the radiating patch and the partial ground plane. The UWB antenna is designed on RO4003 substrate with relative permittivity $\varepsilon_{\mathrm{r}}=3.38$, loss tangent equal to 0.0027 and thickness $h=0.813 \mathrm{~mm}$. The monopole antenna is fed by $50 \Omega$ microstrip line.

\subsection{DMS Band-Stop Filter Design}

DMS plays an important role in designing filters due to several advantages such as size and complexity reduction. It also reduces the radiation loss which enhances the stop band attenuation. The 2-D layout of the DMS filter is shown in Fig. 3. It is considered as a simple slot inserted in the microstrip line. This slot changes the effective capacitance and inductance of the microstrip line which leads to band stop behavior. The dimensions of the DMS filter were optimized to achieve the desired resonant frequency. The simulated S-parameters (return loss and insertion loss) of the DMS filter are plotted in Fig. 4. It is clear that the filter has two rejected frequency bands. The first band is 3.15 to $4 \mathrm{GHz}$ and the second band is 7.9-8.6 GHz.

\subsection{Open Loop Resonant Slot}

The simulated current distribution of the reference antenna at $6 \mathrm{GHz}$ is plotted in Fig. 5 (a). It can be noticed that the surface current is concentrated near the input of the patch and decreases away from the center of the patch. Therefore, by inserting a slot half of wavelength in length at the place where there is the maximum of surface current, band notch features can be accomplished. The open loop resonant slot position and dimensions were selected and
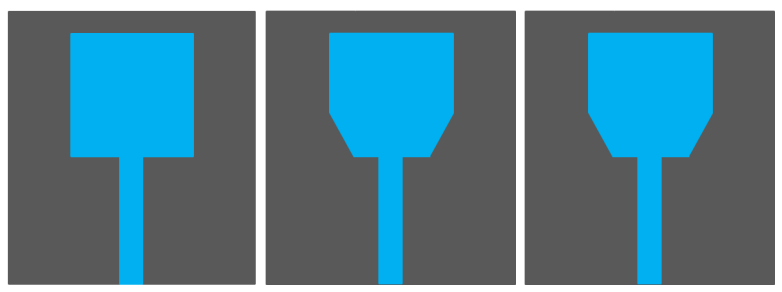

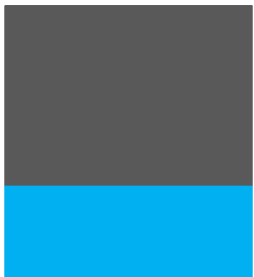

(a)

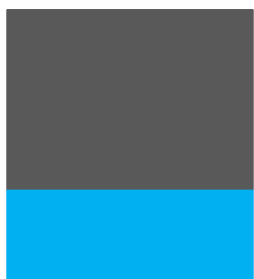

(b)

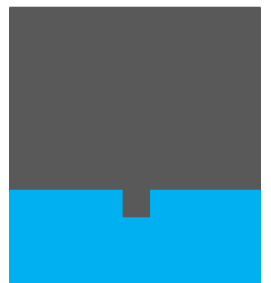

(c)
Fig. 1. UWB antenna layouts - top and bottom : (a) Case I, (b) Case II, (c) Case III.

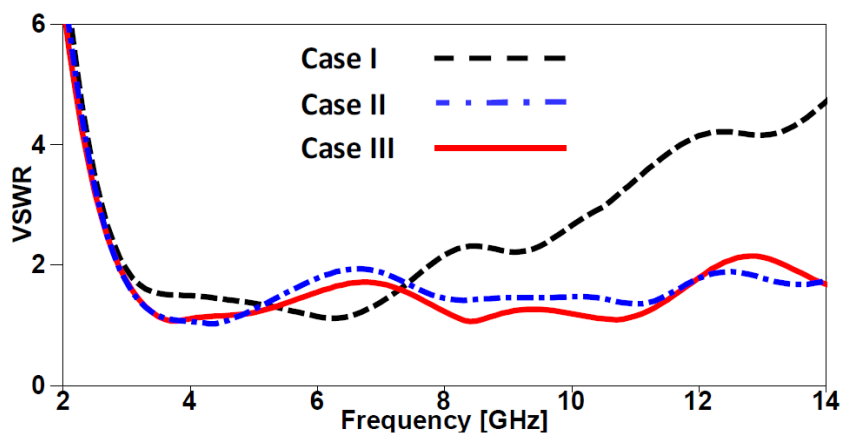

Fig. 2. VSWR of the UWB antenna.

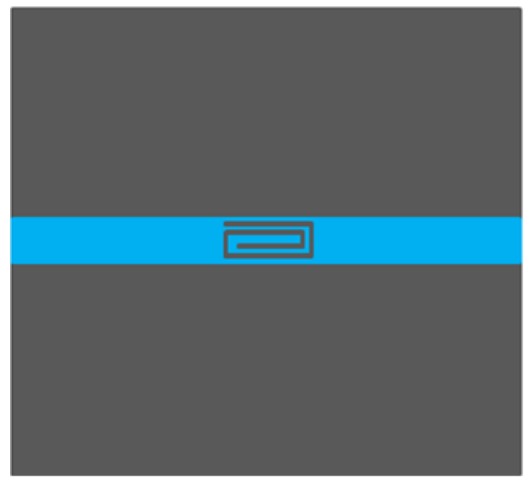

Fig. 3. The layout of DMS band stop filter.

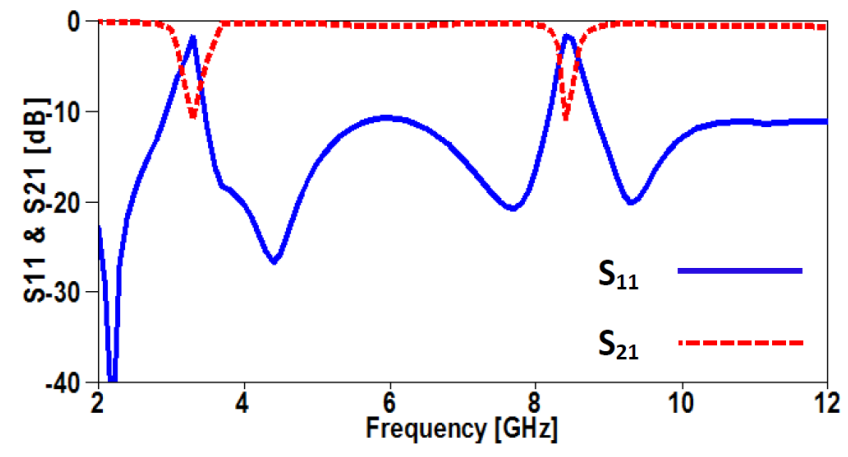

Fig. 4. S-parameters magnitude of the DMS filter. 


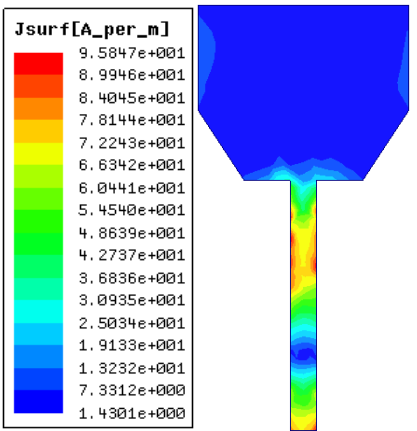

(a)
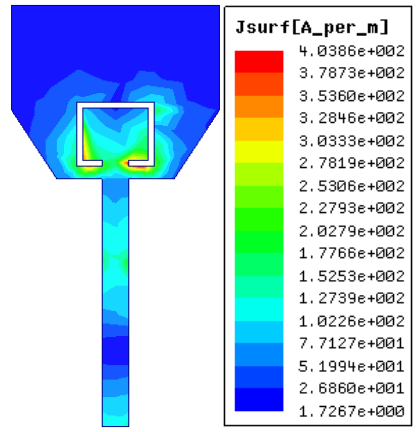

(b)
Fig. 5. Simulated surface current distributions of antenna at $6 \mathrm{GHz}$ : (a) without a slot, (b) with the slot.

optimized to achieve the band notched characteristics. The simulated current distribution at $6 \mathrm{GHz}$ for monopole antenna with the loop resonator is shown in Fig. 5(b) and it is obvious that the surface current is concentrated around the slot, which means that the antenna does not radiate at this frequency band.

\section{Proposed UWB Antenna Design}

The 2-D layout of the proposed UWB monopole antenna is illustrated in Fig. 6. The detailed dimensions are stated in Tab. 1. The antenna consists of the previously investigated UWB monopole antenna with the open loop resonant slot etched in the patch and the DMS filter inserted in the microstrip line. The simulated VSWR of the

\begin{tabular}{|c|c|c|c|c|c|c|c|}
\hline Parameter & $L_{1}$ & $L_{2}$ & $L_{3}$ & $L_{4}$ & $L_{5}$ & $L_{6}$ & $L_{7}$ \\
\hline Value (mm) & 5.6 & 5.2 & 14 & 20 & 4.8 & 5.6 & 6 \\
\hline parameter & $L_{8}$ & $L_{9}$ & $W_{1}$ & $W_{2}$ & $W_{3}$ & $W_{4}$ & $W_{5}$ \\
\hline Value (mm) & 2 & 19 & 16 & 6 & 5 & 3.5 & 1.6 \\
\hline parameter & $W_{6}$ & $W_{7}$ & $W_{8}$ & $W$ & $L$ & $d$ & \\
\hline Value (mm) & 1.2 & 2 & 2 & 32 & 36 & 0.2 & \\
\hline
\end{tabular}

Tab. 1. Dimensions of the proposed antenna structure.

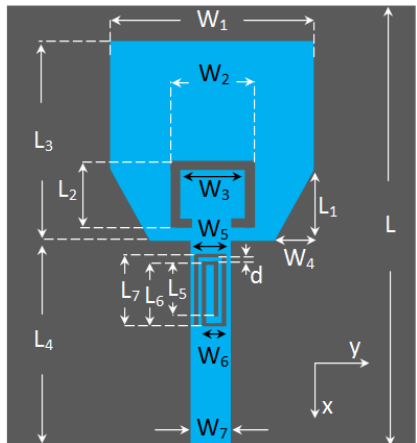

(a)

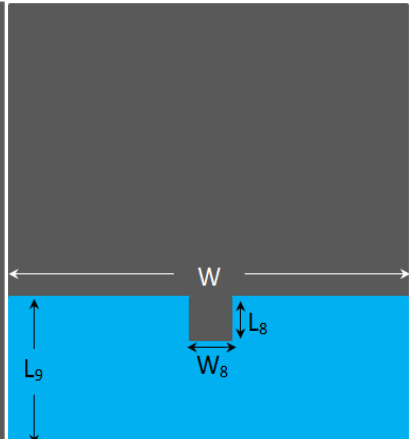

(b)
Fig. 6. The geometry of the proposed UWB antenna: (a) Front view, (b) back view.

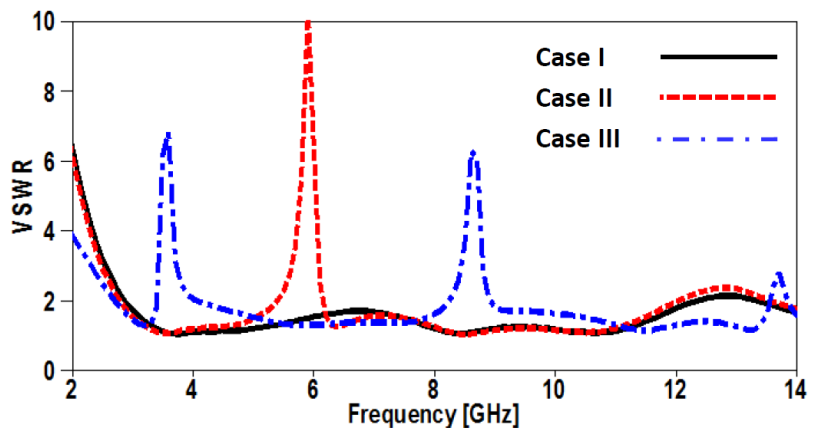

Fig. 7. The VSWR of the proposed antenna for three different cases, see the text.

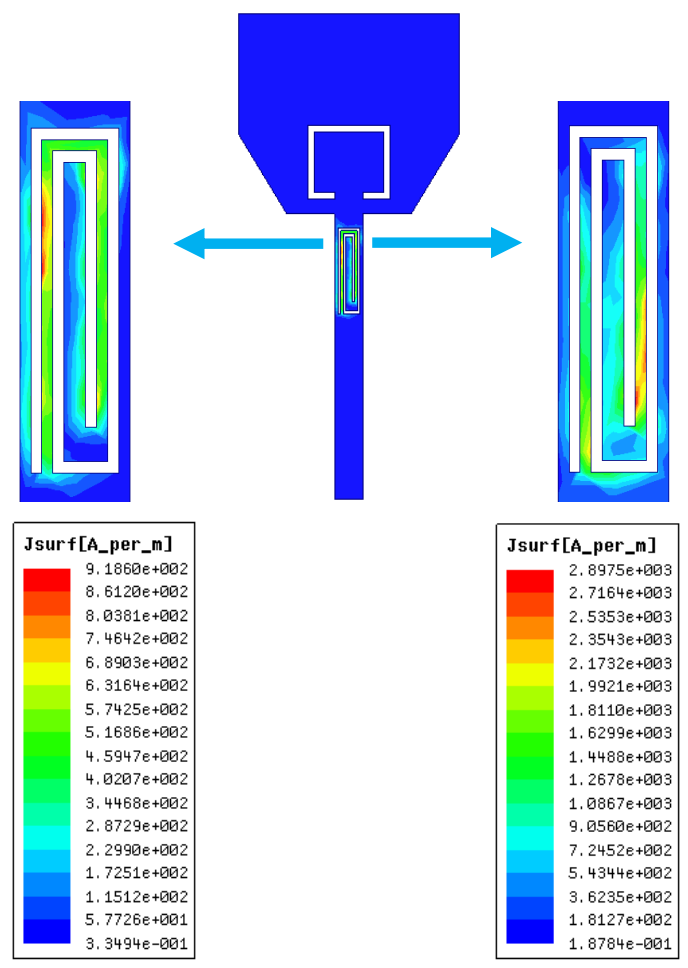

(b)

Fig. 8. Simulated surface current distributions of the antenna with the DMS filter: (a) at $3.4 \mathrm{GHz}$, (b) at $8.4 \mathrm{GHz}$.

particular UWB antenna versions is shown in Fig. 7. Case I corresponds to the response of the reference antenna. Case II represents the antenna with the open loop resonator only. It is clear that the VSWR is lower than 2 except the notched frequency band 5.7-6.3 GHz. Case III represents the antenna with the DMS filter which is embedded in the feeding line only. It can be noticed from the plot that the VSWR is lower than 2 except the two notched frequency bands $3.15-4 \mathrm{GHz}$ and $7.9-8.6 \mathrm{GHz}$.

The simulated current distributions of the UWB monopole antenna with DMS filter at $3.4 \mathrm{GHz}$ and $8.4 \mathrm{GHz}$ are demonstrated in Fig. 8. It is obvious from Fig. 8 that the current is concentrated around the DMS filter and practically no current passes through the patch. This confirms the fact that the DMS acts as dual band-stop filter and the antenna does not radiate at these two frequency bands. 


\section{Experimental Results}

The proposed UWB antenna has been simulated, fabricated and then tested using Agilent N9918A vector network analyzer (VNA). The antenna was fabricated on RO4003 substrate with relative dielectric constant of 3.38, thickness of $0.813 \mathrm{~mm}$ and dielectric loss tangent equal to 0.0027. The photographs of the fabricated antenna are shown in Fig. 9. The VSWR of the antenna was measured and compared with the simulated one as demonstrated in Fig. 10. As seen from the plot, there is a good agreement between basic shapes of simulated and measured VSWR. The measured rejection level in the three notched band is not as good as predicted by simulations. This is with the highest probability caused by fabrication tolerances and by the used SMA connector. The results show that the proposed antenna is working as UWB antenna from $2.7 \mathrm{GHz}$ to $13.45 \mathrm{GHz}$. However, there are three notches at 3.15-4 GHz, 5.7-6.3 GHz and 7.9-8.6 GHz with VSWR which is higher than 2 .

A comparison between simulated and measured realized gain of the proposed triple band notched UWB monopole antenna is illustrated in Fig. 11(a). The average measured realized gain of the UWB antenna is nearly constant around $3 \mathrm{dBi}$, except the three notched frequency bands with values equal $-2 \mathrm{dBi},-1.5 \mathrm{dBi}$ and $-1.1 \mathrm{dBi}$ respectively. The radiation efficiency of UWB antenna is illustrated in Fig. 11(b). It is seen from Fig. 11(b) that the average efficiency of the UWB antenna equals around $85 \%$. However the efficiency of UWB antenna is reduced to $30 \%, 20 \%$ and $30 \%$ at the three notched frequency bands.

The radiation patterns of the proposed antenna in the $x-z$ plane, $y-z$ plane and $x-y$ plane (see the coordinate system in Fig. 6(a)) were measured inside anechoic chamber at $3.1 \mathrm{GHz}, 5.3 \mathrm{GHz}$, and $9.1 \mathrm{GHz}$. The normalized simulated and measured radiation patterns in $x-z, y-z$ and $x-y$ planes of the proposed antenna are shown in Fig. 12 and Fig. 13, respectively. Position angle $\theta=0$ in Figs. 12 and 13 is directed in the positive direction of $x$-axis in (a), $z$-axis in (b), and $x$-axis in (c). It follows from Fig. 12 that the UWB monopole antenna has nearly omnidirectional patterns in $y-z$ plane and almost bi-directional patterns in $x-z$ and $x-y$ planes at the three different frequencies, which implies that the proposed antenna has a large and uniform coverage confirming the fact that the proposed antenna is convenient for UWB application.

Comparison between our proposed antenna and other in literature presented designs in terms of measured values is illustrated in Tab. 2. Table 2 presents notch frequencies, realized gain at these notches. It can be concluded from this comparison that the proposed antenna has compact size and higher bandwidth. The gain at centers of notched band is comparable, or somewhat higher.

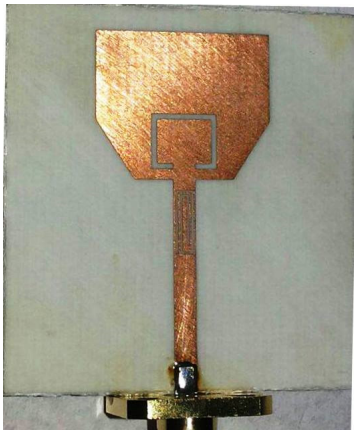

(a)

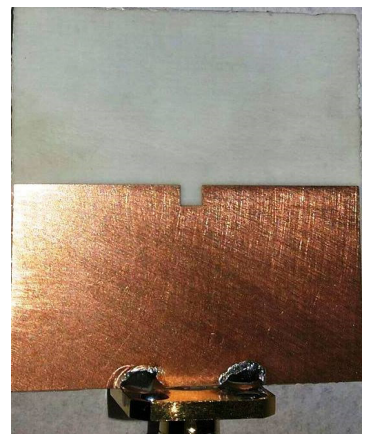

(b)
Fig. 9. Photographs of the fabricated UWB antenna: (a) Front view, (b) back view.

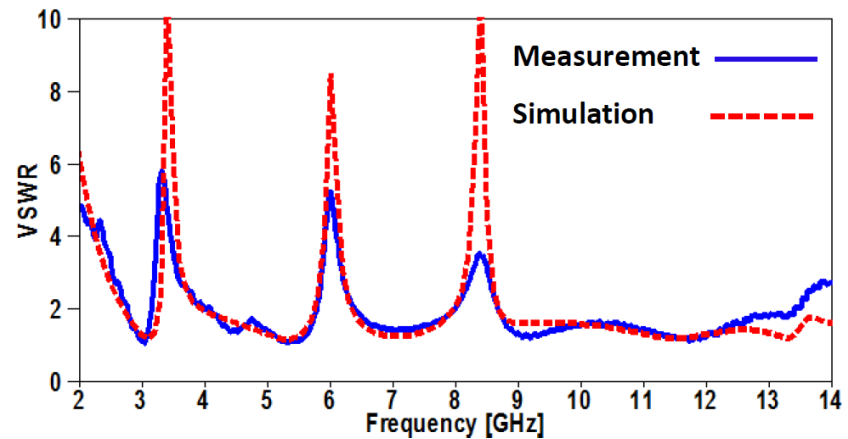

Fig. 10. The simulated and measured VSWR of the optimized structure against frequency.

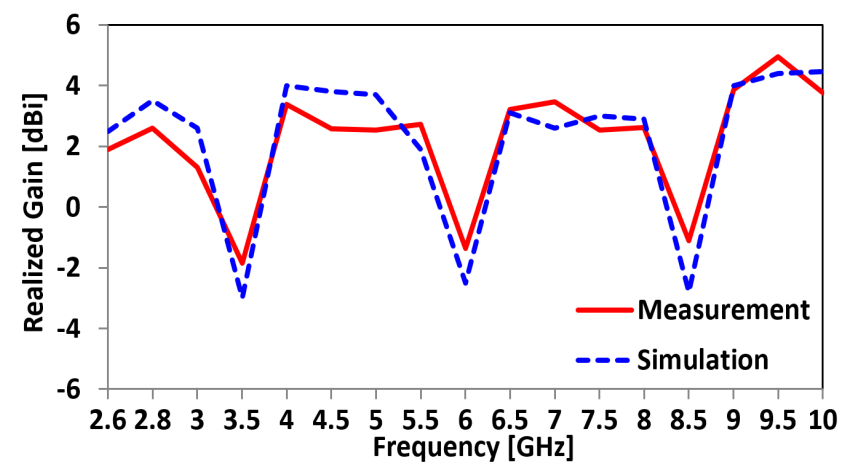

(a)

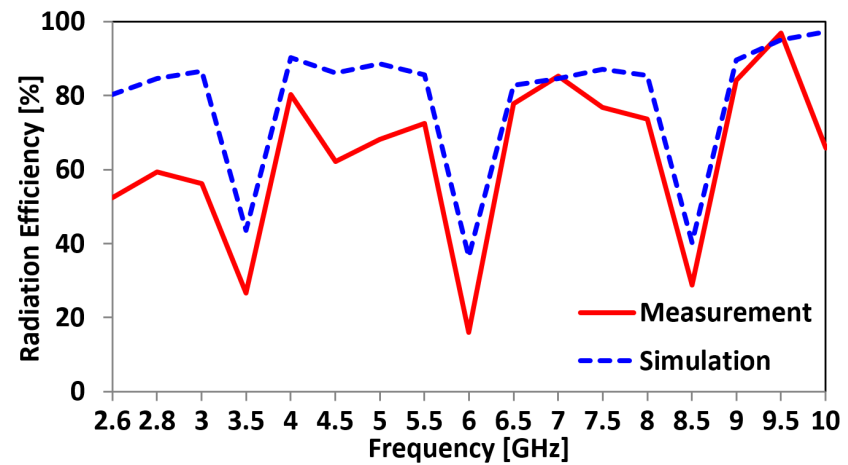

(b)

Fig. 11. The simulated and measured results of the optimized structure against frequency: (a) gain, (b) efficiency. 


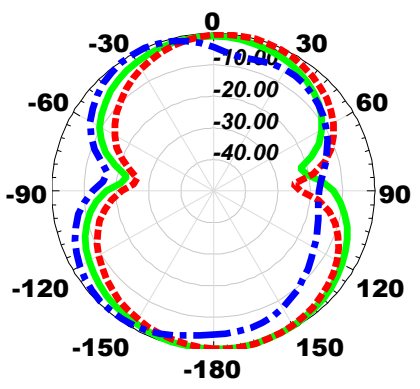

(a)

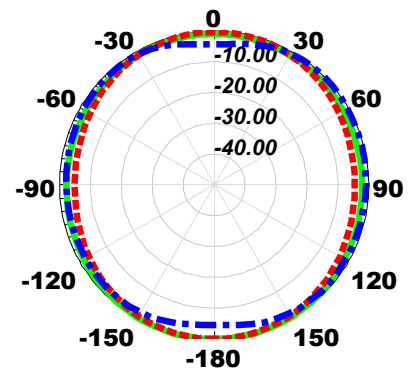

(b)

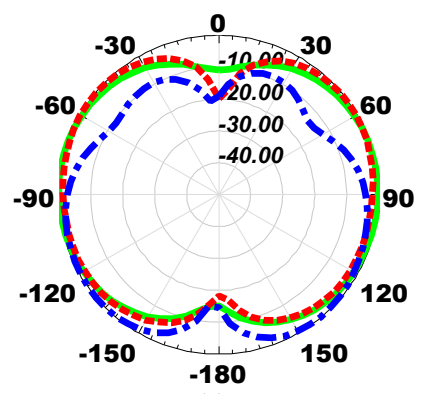

(c)

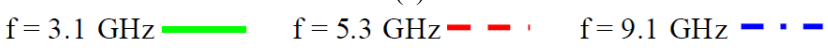

Fig. 12. The simulated normalized radiation patterns at $f=3.1 \mathrm{GHz}, 5.3 \mathrm{GHz}$ and $9.1 \mathrm{GHz}$ : (a) $x-z$ plane, (b) $y-z$ plane, (c) $x-y$ plane.

\begin{tabular}{|c|c|c|c|c|}
\hline & $\begin{array}{c}\text { Size } \\
{\left[\mathrm{mm}^{2}\right]}\end{array}$ & $\begin{array}{c}\text { Frequency } \\
\text { range } \\
{[\mathrm{GHz}]}\end{array}$ & $\begin{array}{c}\text { Notch } \\
\text { frequencies } \\
\text { [GHz] }\end{array}$ & $\begin{array}{c}\text { Realized } \\
\text { gain }[\mathbf{d B i}]\end{array}$ \\
\hline \multirow{3}{*}[16]{} & \multirow{3}{*}{$35 \times 35$} & \multirow{3}{*}{$2.2-12.8$} & 3.54 & -5.6 \\
\hline & & & 5.73 & -0.9 \\
\hline & & & 8.56 & -3 \\
\hline \multirow{3}{*}[17]{} & \multirow{3}{*}{$44 \times 12$} & \multirow{3}{*}{$2.2-11.3$} & 2.4 & -0.5 \\
\hline & & & 3.8 & -1.6 \\
\hline & & & 5.5 & -0.3 \\
\hline \multirow{3}{*}{ [18] } & \multirow{3}{*}{$50 \times 42$} & \multirow{3}{*}{$2-11$} & 3.45 & -5.5 \\
\hline & & & 5.55 & -5 \\
\hline & & & 7.4 & -4.3 \\
\hline \multirow{2}{*}{ [19] } & \multirow{2}{*}{$45 \times 40$} & \multirow{2}{*}{$3-11$} & 4.1 & -3.8 \\
\hline & & & 5.3 & -3.4 \\
\hline \multirow{3}{*}{$\begin{array}{l}\text { This } \\
\text { work }\end{array}$} & \multirow{3}{*}{$36 \times 32$} & \multirow{3}{*}{$2.7-13.4$} & 3.3 & -2 \\
\hline & & & 6 & -1.5 \\
\hline & & & 8.4 & -1.1 \\
\hline
\end{tabular}

Tab. 2. Comparison between different UWB triple-band notched antenna designs.

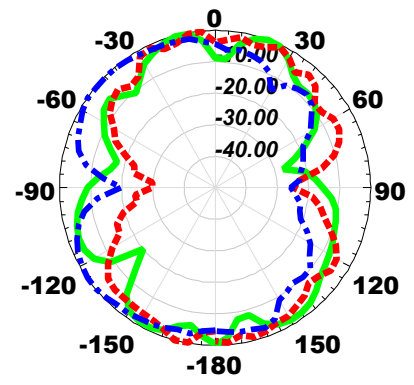

(a)

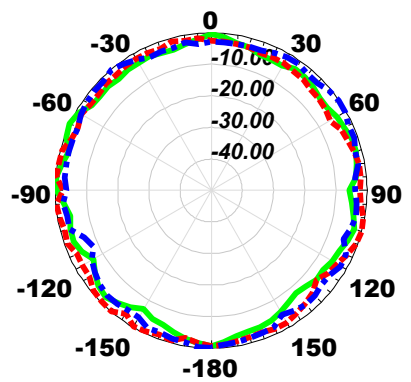

(b)

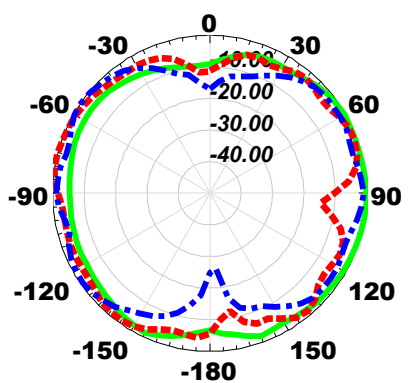

(c)

$\mathrm{f}=3.1 \mathrm{GHz} \quad \mathrm{f}=5.3 \mathrm{GHz}-\mathbf{f}=9.1 \mathrm{GHz}$ - ・

Fig. 13. The measured normalized radiation patterns at $f=3.1 \mathrm{GHz}, 5.3 \mathrm{GHz}$ and $9.1 \mathrm{GHz}$ : (a) $x-z$ plane, (b) $y$-z plane, (c) $x-y$ plane.

\section{Conclusion}

The design of the compact size monopole UWB antenna with triple band notches has been presented. A tapered transition between the rectangular patch and the feeding line has been used to achieve good impedance matching from $2.7 \mathrm{GHz}$ to $13.4 \mathrm{GHz}$. The defected microstrip structure and the open loop slot etched in the radiation patch have been used to produce triple band notches. The three band notches are $3.15-4 \mathrm{GHz}, 5.7-6.3 \mathrm{GHz}$ and 7.9-8.6 GHz for IEEE 502.16 WiMAX band, WLAN band, and ITU respectively. Moreover, good agreement has been achieved between the simulated and measured results. This confirms that the proposed antenna is suitable for UWB applications.

\section{Acknowledgments}

The authors would like to thank the National Telecommunication Institute (NTI) in Egypt for fabricating the 
proposed antenna and to thank Dr. Hadia Elhennawy and Eng. Abdel Hamid Hatem for their support in measuring the radiation characteristics of the fabricated antenna in the anechoic chamber of Ain Shams University's antenna laboratory in Egypt.

The finalizing of the work has been supported by the Grant Agency of the Czech Republic under project No. 17-00607S.

\section{References}

[1] FEDERAL COMMUNICATIONS COMMISSION. First Report and order, Revision of part 15 of the commission's Rule Regarding Ultra-Wideband Transmission System FCC 02-48. 2002.

[2] ALlEN, B., DOHLER, M., OKON, E., et al. (eds.). Ultra Wideband Antennas and Propagation for Communications, Radar and Imaging. Wiley, 2006. ISBN: 978-0-470-03255-8

[3] FONTANA, R. J. Recent system applications of short-pulse ultrawideband (UWB) technology. IEEE Transactions on Microwave Theory and Techniques, 2004, vol. 52, no. 9, p. 2087-2104. DOI: 10.1109/TMTT.2004.834186

[4] WILLIAM, J., NAKKEERAN, R. A compact CPW-fed UWB slot antenna with cross tuning stub. Progress In Electromagnetics Research C, 2010, vol. 13, p. 159-170. DOI: 10.2528/PIERC10022505

[5] ABDElRaheEM, A. M., ABDAlla, M. A., ElREGily, H. A., et al. Coplanar UWB antenna for high speed communication systems. In 2012 International Conference on Engineering and Technology (ICET). Cairo (Egypt), 10-11 Oct. 2012, 5 p. DOI: 10.1109/ICEngTechnol.2012.6396155

[6] ALIPOUR, A., HASSANI, H. R. A novel omni-directional UWB monopole antenna. IEEE Transactions on Antennas and Propagation, 2008, vol. 56, no. 12, p. 3854-3857. DOI: 10.1109/TAP.2008.2007398

[7] ABDELREHEEM, A., ABDALLA, M. Compact curved half circular disc-monopole UWB antenna. International Journal of Microwave and Wireless Technologies, 2016, vol. 8, no. 2, p. 283 to 290. DOI: $10.1017 / \mathrm{S} 1759078714001524$

[8] BOUTEJDAR, A., ABD ELLATIF, W. A novel compact UWB monopole antenna with enhanced bandwidth using triangular defected microstrip structure and stepped cut technique. Microwave and Optical Technology Letters, 2016, vol. 58, no. 6, p. 1514-1519. DOI: $10.1002 / \mathrm{mop} .29820$

[9] ZHAN, K., GUO, Q., HUANG, K. A miniature planar antenna for Bluetooth and UWB applications. Journal of Electromagnetic Waves and Applications, 2010, vol. 24, no. 16, p. 2299-2308. DOI: $10.1163 / 156939310793699109$

[10] BOUTEJDAR, A., IBRAHIM, A. A., BURTE, E. P. Novel Microstrip Antenna Aims at UWB Applications. [Online] Cited 2016-08-31. Available at: http://mwrf.com/passivecomponents/novel-microstrip-antenna-aims-uwb-applications

[11] ZHANG CHAOZHU, JING ZHANG, LIN LI. Triple bandnotched UWB antenna based on SIR-DGS and fork-shaped stubs. Electronics Letters, 2014, vol. 50, no. 2, p. 67-69. DOI: 10.1049/el.2013.2513

[12] MOHAMmed, H. J., ABDUllah, A. S., ALI, R. S., et al. Design of a uniplanar printed triple band-rejected ultra-wideband antenna using particle swarm optimisation and the firefly algorithm. IET Microwaves, Antennas \& Propagation, 2016, vol. 10, no. 1, p. 31-37. DOI: 10.1049/iet-map.2014.0736
[13] SUNG, Y. Triple band-notched UWB planar monopole antenna using a modified $\mathrm{H}$-shaped resonator. IEEE Transactions on Antennas and Propagation, 2013, vol. 61, no. 2, p. 953-957. DOI: 10.1109/TAP.2012.2223434

[14] WANG, J., YIN, Y., LIU, X. Triple band-notched ultra-wideband antenna using a pair of novel symmetrical resonators. IET Microwaves, Antennas \& Propagation, 2014, vol. 8, no. 14, p. 1154-1160. DOI: 10.1049/iet-map.2014.0239

[15] ZHU, F., GAO, S., HO, A. T.S., et al. Multiple band-notched UWB antenna with band-rejected elements integrated in the feed line. IEEE Transactions on Antennas and Propagation, 2013, vol. 61, no. 8, p. 3952-3960. DOI: 10.1109/TAP.2013.2260119

[16] SARKAR, D., SRIVASTAVA K. V., K. SAURAV, K. A compact microstrip-fed triple band-notched UWB monopole antenna. IEEE Antennas and Wireless Propagation Letters, 2014, vol. 13, p. 396 to 399. DOI: 10.1109/LAWP.2014.2306812

[17] LOTFI, P., SOLTANI, S., AZARMANESH, M. Triple band notched UWB CPW and microstrip line fed monopole antenna using broken $\cap$-shaped slot. International Journal of Electronics and Communications. 2011, vol. 65, no. 9, p. 734-741. DOI: 10.1016/j.aeue.2010.11.001

[18] JAGLAN, N., KANAUJiA, B. K., GUPTA, S. D., et al. Triple band notched UWB antenna design using electromagnetic band gap structures. Progress In Electromagnetics Research C, 2016, vol. 66, p. 139-147. DOI: 10.2528/PIERC16052304

[19] KALTEH, A. A., DADASHZADEH, G. R., NASER-MOGHADASI, M., et al. Ultra-wideband circular slot antenna with reconfigurable notch band function. IET Microwaves, Antennas \& Propagation, 2012, vol. 6, no. 1, p. 108-112. DOI: 10.1049/ietmap.2011.0125

\section{About the Authors ...}

Wael ALI received his B.Sc. and M.Sc. in Electronics and Communications Engineering from Arab Academy for Science, Technology and Maritime Transport (AASTMT), Alexandria, Egypt in 2004 and 2007, respectively. He obtained his Ph.D. in Electronics and Communications Engineering from Alexandria University, Alexandria, Egypt in 2012. He is a lecturer in Arab Academy for Science, Technology and Maritime Transport (AASTMT), Alexandria, Egypt. His research interests include smart antennas, microstrip antennas, microwave filters, and metamaterials.

Ahmed A. IBRAHIM was born in 1986. He received the B.Sc. degree, with grade of very good, in Electrical Engineering from the Electronic and Communication Engineering Department, Elminia University, Elminia, Egypt in 2007. He was awarded the M.Sc. degree in Electronic and Communication Engineering from Elminia University in 2011 and the Ph.D. degree from Electronic and Communication Engineering from Minia University in 2014. He is now post-doctoral fellow in the Otto-von-Guericke-Universität Magdeburg, Germany. He is also a lecturer in Electronic and Communication Engineering Department. His research focused on the design and analysis of microstrip antennas, microstrip filters, and its application in wireless communications, metamaterial MIMO antennas and different metamaterial applications in microwave bands. 
Jan MACHAC is a professor at the Department of Electromagnetic Field, Faculty of Electrical Engineering, Czech Technical University in Prague, Czech Republic. His main scientific interests are: investigation of planar passive elements and subsystems of microwave technology, planar antennas, planar microwave filters, propagation of electromagnetic waves in periodic structures, and metamaterials. Prof. Machac is an author or co-author of more than 250 publications in scientific journals and scientific interna- tional and national conferences. He is a Senior Member of IEEE Microwave Theory and Technique Society, member of the IEEE MTT-S Int. Microwave Symposium TPRC, since 2008, member of the TPC of the European Microwave Conference during 1995-1997, and since 2013, reviewer of: IEEE Transactions on Microwave Theory and Techniques, IEEE Microwave and Wireless Components Letters, Electronics Letters, and IET Microwave Antennas and Propagation. 